\title{
ĐÁNH GIÁ KẾT QUẢ ĐIỀU TRI PEMETREXED BƯớC 2 TRONG UNG THƯ BIỂU MÔ TUYẾN CỦA PHỔI GIAI ĐOẠN IV
}

\author{
Lê Thị Vân Anh ${ }^{1}$, Nguyễn Thị Thái Hòa ${ }^{2}$, Nguyễn Văn Hiếu ${ }^{1}$
}

\section{TÓM TẮT}

Mục tiêu: Đánh giá thời gian sống thêm bệnh không tiến triển (PFS) và các tác dụng phụ của phác đồ Pemetrexed bước 2 trên bệnh nhân ung thư biểu mô tuyến của phổi giai đoạn IV tại Bênh viên $\mathrm{K}$ từ tháng $1 / 2017$ đến tháng $8 / 2021$. Đối tượng và phương pháp: Hồi cứu kết hợp tiến cứu có theo dõi dọc trên33 bệnh nhân ung thư biểu mô tuyến của phổi giai đoan IV đước điều trị Pemetrexed sau tiến triển hóa trị bước 1 bộ đôi có platinum. Kết quả: Trung vị sống thêm bệnh không tiến triển là 3.4 tháng. Phân tích dưới nhóm cho thấy trung vị PFSkhông khác nhau giữa các phân nhóm tuổi và giới $(p=0.198$ và $p=0.283$ $>$ 0.05). Trung vị PFS của nhóm có thể trạng $E C O G=0-1$ cao hơn nhóm $E C O G=2$, khác biệt có ý nghĩa thống kê $(p=0.029)$. Thuốc dung nạp tốt. Độc tính chủ yếu gồm thiếu máu, tăng men gan, mệt mói, và buồn nôn đều ở mức độ I, II. Không ghi nhần độc tính độ III, IV. Kết luận: Phác đồ Pemetrexed bước 2 là lựa chọn điều trị phù hợp, hiệu quả với dữ liệu độc tính an toàn cho bệnh nhân ung thư biểu mô tuyển của phổi sau thất bại hóa chất bước 1 bộ đôi có platinum.

Tư khóa: Ung thư biểu mô tuyến của phổi, điều trị bước 2, sống thêm bệnh không tiến triển.

\section{SUMMARY}

EVALUATION OF THE TREATMENT OUTCOMES OF PEMETREXED IN SECONDLINE TREATMENT OF LUNG ADENOCARCINOMA STAGE IV

Objective: To evaluateprogression-free survival and side effects of Pemetrexed in second-line treatment of patients with lung adenocarcinoma stage IV at K hospital from January 2017 to August 2021. Methods: Combined retrospective and prospectivelongitudinal study in 33 patients with lung adenocarcinoma stage IV treated with Pemetrexed after progression on platinum-containing first-line chemotherapy. Results: Median progression-free survival was 3.4 months. There were no significant differences in median PFS between subgroups in terms of age and sex. The median PFS of patients with better performance status (ECOG) was superior compared to those with poorer ECOG $(p=0.029)$. Toxicity: The regimen was well tolerated. The most common toxicities were anemia, elevated

\footnotetext{
${ }^{1}$ Trường Đại học Y Hà Nội

²Bênh viên $K$

Chịu trách nhiệm chính: Lê Thị Vân Anh

Email: vanhle.hmu@gmail.com

Ngày nhận bài: 18.8 .2021

Ngày phản biện khoa học: 13.10.2021

Ngày duyệt bài: 22.10.2021
}

transaminases, fatigue, and nausea which all at grade 1-2 toxicity. No patients experienced grade 3-4 toxicity. Conclusion: Pemetrexed is an reasonable, effective, and safe optionfor the second-line treatment of metastatic lung adenocarcinoma priorly treated with platinum-containing chemotherapy.

Keywords: Lung adenocarcinoma, second-line treatment, progression-free survival.

\section{I. ĐĂTT VẤN ĐỀ}

Ung thư phổi (UTP) là bệnh lý ác tính thường gặp và là nguyên nhân gây tử vong hàng đâu do ung thư trên phạm vi toàn câu. Theo Globocan 2018, tại Việt Nam, UTP đứng hàng thứ 2 chỉ sau ung thư gan với tổng số ca mới mắc và tử vong lần lượt là 23667 (14.4\%) và 20710 (18.0\%). Tiên lượng sống thêm của UTP vẫn còn rất hạn chế, số bệnh nhân UTP đạt được thời gian sông thêm từ 5 năm trở lên chỉ khoảng 19\% [1], [2], [3]. UTP được chia thành 2 nhóm: UTP tế bào nhỏ và UTP không tế bào nhỏ (UTPKTBN). Ung thư biểu mô tuyến của phổi (UTBMTP) thuộc nhóm UTPKTBN là tuýp thường gặp nhất, chiếm 38.5\% số trường hợp UTP [4].

Mặc dù khoa học đã có nhiêu tiến bộ trong phát hiện và chẩn đoán sớm UTP, nhưng đa phân bệnh nhân tại thời điểm chẩn đoán đã ở giai đoạn muộn, có di căn xa. Khi đó, rào cản về gánh nặng $u$, thể trạng và tuổi tác khiến việc điều trị gặp nhiêuu khó khăn. Trong suốt thập kỷ qua, những nỗ lực không ngừng đặt rađể tìm ra các thuốc mới, các tuân tự điều trị nhằm cải thiện kết quả sống thêm cho bệnh nhân UTPKTBN giai đoạn di căn. Kết quả cải thiện đáng kể nhất phải kể đến sự ra đời của các thuốc điều trị đích, tuy nhiên chỉ dành cho phân nhỏ nhóm bệnh nhân có đột biến EGFR nhạy thuốc hoặc tái tổ hợp gen ALK. Đối với nhóm không có hoặc không rõ tình trạng đột biến, liệu pháp miễn dịch đơn thuân hoặc phối hợp hóa chất cũng đem lại những kết quảkỳ vọng. Tuy vậ̂y, hóa chất vẫn là điêu trị cơ bản do tính có sẳn cũng như chi phí điều trị bệnh nhân có thể tiếp cận được [5].

Điều trị bước 2 UTPKTBN giai đoạn di căn sau khi tiến triển với hóa trị bước 1 là cân thiết để giúp kéo dài thời gian sống thêm cho bệnh nhân. Ớ bước này, thể trạng bệnh nhân đã kém đi nhiêu do trải qua nhiêuu chu kỳ điêuu trị trước đó, nên mục tiêu là lựa chọn các thuốc vừa có hiệu 
quả, dung nap tốt và ít độc tính tích lũy. Pemetrexed- một thuốc kháng ung thư nhóm folate áp dụng với nhóm UTPKTBN không vảy, đã cho thấy vai trò trong điêu trị bước 2 nhờ hiệu quả điều trị, độc tính thấp và tiện lợi khi sử dụng. Nghiên cứu ngẫu nhiên pha III của Hannah (2004) và Pujol (2007) so sánh đối đâu Pemetrexed và Docetaxel trong điều trị bước 2 cho thây hiệu quả tương đương về thời gian sống thêm giữa 2 thuốc, nhưng độc tính do Pemetrexed dễ quản lý hơn Docetaxel [6], [7].

Tại bệnh viện K, việc điêuu trị Pemetrexed đơn trị bước 2 cho ung thư biểu mô tuyến của phổi sau tiến triển hóa chất bước 1 đã được áp dụng trong những năm gân đây. Tuy nhiên tại Việt Nam, còn ít dữ liệu đánh giá tính hiệu quả và mức độ an toàn của phác đồ này. Vì vậy, chúng tôi tiến hành nghiên cứu này nhằm 2 mục tiêu:

1. Đánh giá thời gian sông thêm bệnh không tiến triên của phác đồ Pemetrexed bước 2 trên bệnh nhân ung thư biểu mô tuyến của phôi giai đoạn IV

2. Nhận xét một số tác dụng phụ không mong muốn của phác đồ

\section{II. ĐỐI TƯợNG VÀ PHƯƠNG PHÁP NGHIÊN CỨU}

2.1 Đối tượng nghiên cứu. Gồm 33 bệnh nhân UTBMTP giai đoạn IV tiến triển sau điêu trị hóa chất bước 1 , được điêu trị bằng Pemetrexed bước 2 từ tháng 1/2017 đến tháng 8/2021 tại Bệnh viện K.

\section{Tiêu chuấn lựa chọn:}

Chẩn đoán mố bệnh học là ung thư biểu mô tuyến của phổi.

Không có hoặc không biết tình trạng đột biến EGFR hoặc ALK.

Bệnh nhân được chẩn đoán ung thư biểu mô tuyến của phổi giai đoạn IV tiến triển sau hóa trị bước 1 bộ đôi có platinum và được điêu trị bước 2 bằng Pemetrexed, tối thiểu 2 đợt.

Chỉ số toàn trạng ECOG 0-2.

Không mắc bệnh ung thư khác.

Chức năng gan, thận, tủy xương trong giới hạn cho phép hóa trị.

Có ít nhất 1 tổn thương đích đo được để đánh giá đáp ứng theo tiêu chuẩn RECIST.

Bệnh nhân có hồ sơ bệnh án theo dõi đây đủ thông tin

\section{Tiêu chuẩn loai trư:}

Trước đó đã điều trị Pemetrexed.

Bỏ dở điêuu trị hoặc không theo đúng phác đồ điều trị vì lý do không phải chuyên môn.

Có tình trạng tràn dịch màng phổi hoặc di căn não không kiểm soát được.
Không có hồ sơ lưu trữ đây đủ.

\subsection{Phương pháp nghiên cứu:}

Thiết kế nghiên cứu:Mô tả hồi cứu kết hợp tiến cứu, có theo dõi dọc.

Thu thập thông tin: Thu thập thông tin theo mẫu bệnh án nghiên cứu thống nhất, dựa trên thông tịn hồi cứu từ bệnh án lưu trữ.

Các bước tiến hành:chọn mẫu thuận tiện.

- Thu thập thông tin chung và ghi nhận đặc điểm LS, CLS trước điều trị Pemetrexed.

- Điều trị, đánh giá đáp ứng khách quan tổn thương theo tiêu chuẩn RECIST.

- Đánh giá độc tính của phác đồ theo tiêu chuẩn CTCAE v4.0.

2.3 Phân tích và xử lý số liệu: Các thông tin thu thập được mã hóa và xử lý trên phân mềm SPSS 20.0, phân tích thời gian sống thêm theo phương pháp Kaplan-Meier.

2.4 Đạo đức nghiên cứu: Phác đồ có trong hướng dẫn điều trị UTP của Bộ Y Tế.

Bệnh nhân tự nguyện tham gia nghiên cứu.

\section{KẾT QUẢ NGHIÊN CứU}

Bảng 1. Đặc điểm bệnh nhân

\begin{tabular}{|c|c|c|}
\hline 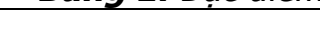 & $\mathbf{n}$ & $\%$ \\
\hline Giới: & 27 & 81.8 \\
\hline Nữ & 6 & 18.2 \\
\hline Nhóm tuối: $\leq 49$ & 5 & 15.2 \\
\hline $50-59$ & 12 & 36.4 \\
\hline$\geq 60$ & 16 & 48.5 \\
\hline ECOG: $0-1$ & 27 & 81.8 \\
\hline 2 & 6 & 18.2 \\
\hline
\end{tabular}

Nhân xét: Tuối mắc bệnh trung bình $58.3 \pm$ 7.6, tuổi thấp nhất 42 và tuổi cao nhất 75 tuổi.

Tuổi càng cao nguy cơ mắc bệnh càng cao. Nhóm $\geq 60$ tuổi chiếm tỷ lệ mắc cao nhất là 48.5\% trong khi nhóm $\leq 49$ tuổi chỉ chiếm 15.2\%.

UTP là bệnh lý gặp chủ yếu ở nam giới (tỷ lệ nam/nữ $=4.5 / 1$ ).

Phân lớn bệnh nhân có chỉ số toàn trạng ECOG từ 0-1, chiếm tỷ lệ $81.8 \%$.

Bảng 2. Vị trí di căn

\begin{tabular}{|c|c|c|}
\hline Vị trí & $\mathbf{n}$ & $\mathbf{0}$ \\
\hline Phối & 12 & 36.4 \\
\hline Xương & 15 & 45.5 \\
\hline Màng phối & 12 & 36.4 \\
\hline Gan & 4 & 12.1 \\
\hline Não & 3 & 9.1 \\
\hline Thượng thận & 2 & 6.1 \\
\hline $\begin{array}{c}\text { Khác (hạch cô, phân } \\
\text { mềm, hạch nách..) }\end{array}$ & 7 & 21.2 \\
\hline Số vị trí di căn & & \\
\hline Di căn 1 vị trí & 9 & 27.3 \\
\hline Di căn $\geq 2$ vị trí & 24 & 72.7 \\
\hline
\end{tabular}


Nhân xét: Trong các vị trí di căn, xương, phổi và màng phổi gặp phổ biến nhất, chiếm tỷ lê lần lượt là $45.5 \%, 36.4 \%$ và $36.4 \%$. Đa phần bệnh nhẩn đã di căn nhiều vị trí, số bệnh nhân có tổng vị trí di căn $\geq 2$ chiếm $72.7 \%$.

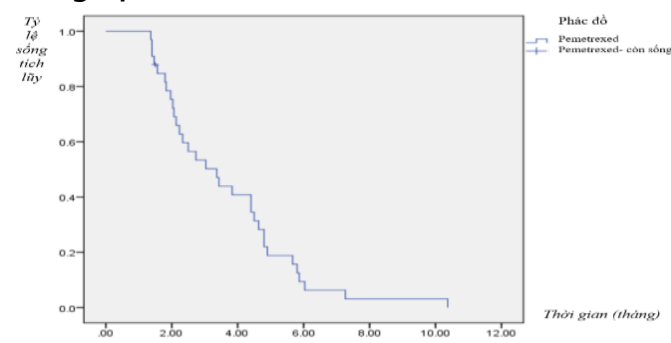

Biểu đồ 1. Kêt quả sông thêm bệnh không tiến triên

Nhận xét: Những bệnh nhân ung thư biểu mô tuyến của phổi giai đoạn IV tiến triển bước 1 được điêu trị bằng Pemetrexed đơn trị bước 2 có trung vị thời gian sống thêm bệnh không tiến triển là $3.4 \pm 0.7$ tháng, thấp nhất là 1.37 tháng và cao nhất là 10.37 tháng.
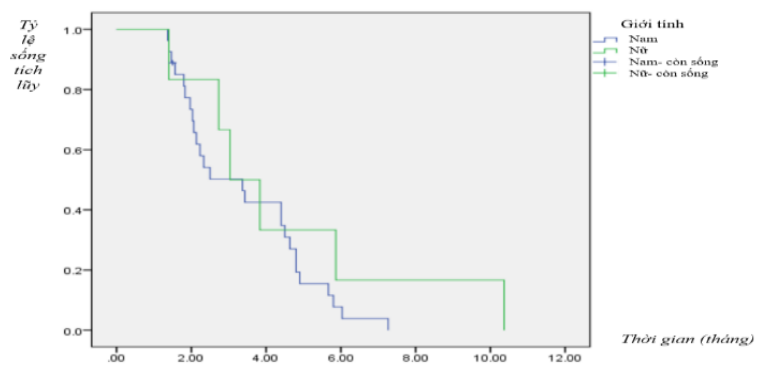

Biếu đồ 2. Sông thêm bệnh không tiến triên theo giói

Nhận xét: Trung vị thời gian sống thêm bệnh không tiến triển ở nam là $3.376 \pm 0.759$; ở nữ là $3.033 \pm 0.674$. Sự khác biệt không có ý nghĩa thống kê $(\mathrm{p}=0.283)$.

Biểu đố 3. Sống thêm bệnh không tiến triên theo chi số toàn trạng ECOG PS

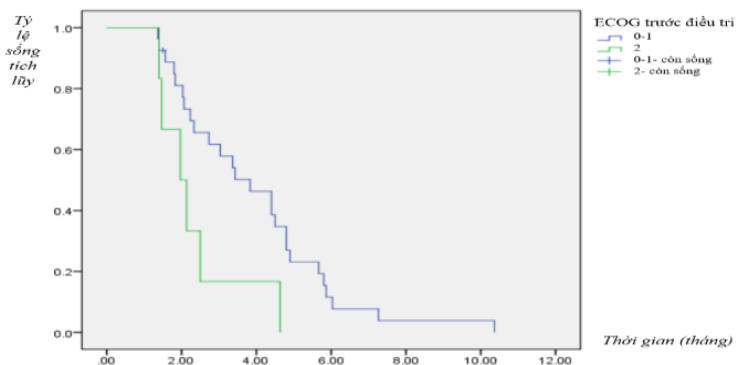

Nhận xét: Trung vị sống thêm bệnh không tiến triển ở nhóm bệnh nhân ECOG 0-1 là 3.833 \pm 0.693 tháng cao hơn nhóm ECOG 2 là $1.967 \pm$ 0.408 tháng. Sự khác biệt có ý nghĩa thống kê $(p=0.029<0.05)$.

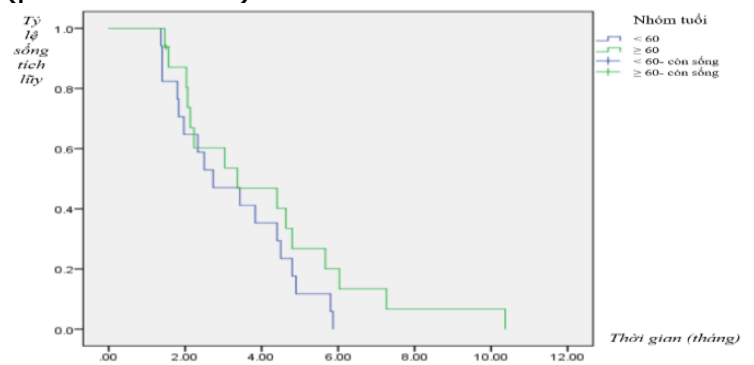

Biểu đồ 4. Sống thêm bẹnh không tiến triên theo nhóm tuôi

Nhận xét: Trung vị sống thêm bệnh không tiến triển ở nhóm < 60 tuổi là $2.733 \pm 0.755$ tháng và nhóm $\geq 60$ tuổi là $3.367 \pm 1.39$ tháng. Sự khác biệt không có ý nghĩa thống kê ( $p=0.198)$

Bảng 3. Tác dụng không mong muốn

\begin{tabular}{|c|c|c|c|c|c|c|c|c|c|c|}
\hline \multirow{2}{*}{$\begin{array}{l}\text { Độc tính } \\
(\mathrm{n}=144)\end{array}$} & \multicolumn{2}{|c|}{ Độ I } & \multicolumn{2}{|c|}{ Độ II } & \multicolumn{2}{|c|}{ Đô III } & \multicolumn{2}{|c|}{ Độ IV } & \multicolumn{2}{|c|}{ ĐộV } \\
\hline & $\mathbf{n}$ & $\%$ & $\mathbf{n}$ & $\%$ & $\mathbf{n}$ & $\%$ & $\mathbf{n}$ & $\%$ & $\mathbf{n}$ & $\%$ \\
\hline Thiều máu (Hb) & 22 & 15.3 & 1 & 0.7 & 0 & 0 & 0 & 0 & 0 & 0 \\
\hline Hạ bạch cầu & 1 & 0.7 & 0 & 0 & 0 & 0 & 0 & 0 & 0 & 0 \\
\hline Ha bạch câu TT & 0 & 0 & 0 & 0 & 0 & 0 & 0 & 0 & 0 & 0 \\
\hline Hạ tiếu cầu & 0 & 0 & 0 & 0 & 0 & 0 & 0 & 0 & 0 & 0 \\
\hline Tăng men gan & 32 & 22.2 & 3 & 2.1 & 0 & 0 & 0 & 0 & 0 & 0 \\
\hline Tăng creatinin & 1 & 0.7 & 0 & 0 & 0 & 0 & 0 & 0 & 0 & 0 \\
\hline Mệt mỏi $(n=33)$ & 7 & 21.2 & 3 & 9.1 & 0 & 0 & 0 & 0 & 0 & 0 \\
\hline Buồn nôn $(n=33)$ & 7 & 21.2 & 1 & 3 & 0 & 0 & 0 & 0 & 0 & 0 \\
\hline Nôn $(n=33)$ & 4 & 12.1 & 0 & 0 & 0 & 0 & 0 & 0 & 0 & 0 \\
\hline Tiêu chảy $(n=33)$ & 2 & 6.1 & 0 & 0 & 0 & 0 & 0 & 0 & 0 & 0 \\
\hline
\end{tabular}

Nhận xét: Trên hệ huyết học: độc tính thiếu máu ghi nhận $16 \%$ hạ độ I, II, không có bệnh nhân nào thiếu máu từ độ III trở lên. Các độc tính về hạ bạch cầu, bạch cầu trung tính và tiểu cầu không đáng kể.

Chức năng gan thận: trong 144 chu kỳ, có
$24.3 \%$ xuất hiện tăng men gan độ I, II. Chức năng thận ít bị ảnh hưởng.

Trong số 33 bệnh nhân, mệt mỏi và buồn nôn khá thường gặp. $30.3 \%$ bệnh nhân mệt mỏi mức độ I, II và $24.2 \%$ bệnh nhân buồn nồn mức độ I, II. 


\section{BÀN LUÂN}

4.1 Đặc điểm bệnh nhân. Trong số 33 bệnh nhân nghiên cứu của chúng tôi, tỷ lệ mắc UTP tăng dân theo tuổi. Nhóm $\geq 60$ tuổi chiếm tỷ lệ mắc cao nhất 48.5\%.Bênh chủ yếu hay găp ở nam giới. Kết quả này phù hợp với nhiều nghiên cứu trước đây về UTP [6], [8].

Việc đánh giá chỉ số toàn trạng trước điều trị là quan trọng để xác định bệnh nhân nào đủ khả năng tiếp nhận điều trị hóa chất. Theo hướng dẫn của NCCN, những bệnh nhân có điểm ECOG PS $\leq$ 2 hoặc KPS $\geq 60 \%$ có thể được chỉ định điều trị hóa chất. Trong nghiên cứu của chúng tôi, hầu hết bệnh nhân có chỉ số ECOG PS từ 0-1, chiếm $81.8 \%$. Số bệnh nhân ECOG 2 chiếm $18.2 \%$.

4.2 Vị trí di căn . Vị trí di căn hay gặp nhất là ở xương, phổi, màng phổi. Đa phân bênh nhân đã di căn nhiều vị trí, số bệnh nhân có tổng vị trí di căn $\geq 2$ chiếm $72.7 \%$. Điều này phù hợp với tình trang bênh ở giai đoan muôn đã thất bại với liệu pháp điều trị trước đó, đồng thời cũng cho thấy sự phức tạp của bệnh và gánh nặng cân phải tìm ra phương án điều trị phù hợp.

4.3 Kết quả điều trị. Trung vị PFS trong nghiên cứu của chúng tôi là 3.4 tháng. Khi đánh giá kết quả điều trị Docetaxel bước 2, nghiên cứu của Trần Nguyên Bảo (2014) cho kết quả PFS trung bình là 5.7 tháng; Trên thế giới, nghiên cứu ngẫu nhiên pha III của Hanna và cộng sự (2004) so sánh đối đầu kết quả điều trị của Pemetrexed và Docetaxel bước 2sau thất bại hóa chất trước đó cho thấy trung vị PFS tương đương nhau 2.9 tháng [6], [7]. Lý giải cho kết quả sống thêm bệnh không tiến triển trong nghiên cứu của chúng tôi thấp hơn của tác giả Trần Nguyên Bảo (2004) và Nguyễn Thị Hương (2019) là do nhóm bệnh nhân trong nghiên cứu của chúng tôi chỉ bao gồm bệnh nhân ở giai đoạn IV, đã di căn nhiều vị trí và tới gần $20 \%$ số bệnh nhân có chỉ số toàn trạng $E C O G=2$; trong khi đó, nhóm bệnh nhân của 2 tác giả trên bao gồm cả giai đoạn III và IV, đa phần di căn 1 vị trí và có thể trạng tốt hơn (không có bệnh nhân nào ECOG PS = 2) [9]. Kết quá của chúng tôi cao hơn một chút so với kết quả trong nghiên cứu của Hanna (2019), có thể do trong nghiên cứu của Hanna, thời điểm đánh giá đáp ứng điều trị nghiêm ngặt hơn, bệnh nhân theo dõi và giám sát chặt chẽ nên sớm phát hiện được tình trạng bênh tiến triển.

Khi phân tích dưới nhóm, trung vị PFS không khác biệt giữa nam và nữ, giữa bệnh nhân $<60$ tuổi và $\geq 60$ tuổi $(p=0.198$ và $p=0.283>0.05)$. Tuy nhiên, kết quả này ở nhóm bệnh nhân có thể trạng tốt hơn (ECOG=0-1) cao hơn có ý nghĩa với nhóm bệnh nhân có thể trạng kém $(E C O G=2)(p=0.029)$. Bệnh nhân có thể trạng tốt hơn liên quan đáng kể đến viêc tăng dung nạp hóa chất, liều được sử dụng tối đa, độc tính cũ̉ng có thể thấp hơn vì vậy giúp cải thiện được PFS.

4.4 Tác dụng phự không mong muốn. Độc tính trên hệ huyết học, gan thận chủ yếu gồm thiếu máu, tăng men gan với tỳ lệ lần lượt là $16 \%$ và $24.3 \%$ mức độ I-II. Không ghi nhận trường hợp nào độ III, IV. Nghiên cứu của Nguyển Thi Hương (2019) cho thây độc tính thiếu máu (hạ $\mathrm{Hb}$ ) và hạ bạch cầu trong điều trị Docetaxel bước 2 là $24.8 \%$ và $28.9 \%$. Tỷ lệ này cao hơn trong nghiên cứu của chúng tôi. Điều này phù hợp với các so sánh đối đầu 2 thuốc điều trị bước 2 Docetaxel và Pemetrexed trên thế giới, Pemetrexed có dữ liệu độc tính an toàn hơn Docetaxel [6], [7]. Tỷ lệ tăng men gan trong nghiên cứu của chúng tôi cao hơn các nghiên cứu về điều trị Pemetrexed đơn trị khác [5], [6], [7]. Tuy nhiên hầu hết bệnh nhân găp phải tình trang tăng men gan trong nghiên cứu của chúng tôi đều có liên quan tới di căn gan và bênh lý viêm gan đi kèm. Có 2 bệnh nhân trong số đó phải trì hoãn điều trị hóa chất 1 tuần, nhưng sau đó tiếp tục điều trị bình thường.

Trong các độc tính ngoài hệ huyết học, gan thận, tỷ lệ bệnh nhân gặp phải mệt mỏi, buồn nôn khi điêu trị Pemetrexed thường gặp nhất. Tuy nhiên chỉ ở mức độ nhẹ, không đáng lo ngại.

\section{KẾT LUẬN}

Qua nghiên cứu 33 bệnh nhân ung thư biểu mô tuyến của phổi được điều trị phác độ Pemetrexed sau tiến triển với hóa chất bước 1 tại Bệnh viện $\mathrm{K}$ từ tháng $1 / 2017$ đến tháng 8/2021, chúng tôi rút ra một số kết luận sau:

Trung vị PFS là 3.4 tháng.

Trung vị PFS không khác biệt về giới và tuổi, nhưng cao hơn có ý nghĩa ở nhóm có thể trạng tốt $(E C O G=0-1)$ so với nhóm có thể trạng kém hơn $(E C O G=2)(p=0.029)$.

Thuốc dung nạp tốt, độc tính trên hệ huyết học và gan thận chủ yếu gồm thiếu máu, tăng men gan. Độc tính ngoài ra hay gặp là mệt mỏi, buồn nôn. Tất cả đều được ghi nhận ở mức độ nhẹ (độ I, II).

\section{TÀI LIỆU THAM KHẢO}

1. Trần Văn Thuấn (2019), Hướng dẫn chẩn đoán và điều trị bệnh ung thư thường gặp, Nhà xuất bản Y học, Hà Nội.

2. International Agency for Research on Cancer (2018). Globocan 2018-Vietnam. WHO.

3. National Comprehensive Cancer Network 
(NCCN) (2020), Non-small cell lung cancer, NCCN Clinical Practice Guidelines in Oncology, Version 3.2020

4. Dela Cruz C.S., Tanoue L.T., and Matthay R.A. (2011). Lung Cancer: Epidemiology, Etiology, and Prevention. Clinics in Chest Medicine, 32(4), 605-644.

5. Tomasini P., Barlesi F., Mascaux C., et al. (2016). Pemetrexed for advanced stage nonsquamous non-small cell lung cancer: latest evidence about its extended use and outcomes:. Therapeutic Advances in Medical Oncology.

6. Hanna N., Shepherd F.A., Fossella F.V., et al. (2004). Randomized phase III trial of pemetrexed versus docetaxel in patients with non-small-cell lung cancer previously treated with chemotherapy. J Clin Oncol, 22(9), 1589-1597.

7. Pujol J.-L., Paul S., Chouaki N., et al. (2007). Survival without common toxicity criteria grade $3 / 4$ toxicity for pemetrexed compared with docetaxel in previously treated patients with advanced nonsmall cell lung cancer (NSCLC): a risk-benefit analysis. J Thorac Oncol, 2(5), 397-401.

8. Bùi Công Toàn- Hoàng Đình Chân (2008), Bênh ung thư phổi, Nhà xuất bản $Y$ hoc.

9. Trânn Nguyên Bảo (2014). Đánh giá hiệu quả điều tri Docetaxel trong điêu tri bước 2 UTPKTBN tai Bênh viên Ung Bướu Hà Nội. Luân văn thạc sĩ Y học, Đ̇ại Học Y Hà Nội.

\title{
TÌNH TRẠNG CĂNG THẲNG CỦA NHÂN VIÊN Y TẾ TẠI MộT SỐ BÊNH VIÊ̂N ĐIỀU TRI BỆNH NHÂN COVID-19 TẠI THÀNH PHỐ HỒ CHÍ MINH NĂM 2021
}

\author{
Vũ Thị Cúc ${ }^{1}$, Nguyễn Phúc Thành Nhân ${ }^{1}$, Nguyễn Xuân Chi ${ }^{2}$, \\ Nguyễn Võ Minh Hoàng ${ }^{2}$, Võ Văn Thắng ${ }^{1,3}$, Nguyễn Minh Quân ${ }^{2}$
}

\section{TÓM TẮT}

Đă̆t vấn đề: Nhân viên y tế là đối tượng tiếp xúc trực tiếp với cảm xúc tiêu cực ở mức độ cao dường như làm tăng nguy cơ dẫn đến hậu quả lâu dài như căng thẳng thứ phát, các triệu chứng trầm cảm hoăc kiệt sức nghề nghiệp với các kết quả bất lợi đến chất lượng chăm sóc sức khỏe. Mục tiêu: Đánh giá mức đổ căng thẳng của nhân viên y tế và môt số yếu tố liển quan tại một số bệnh viện điều trị bệnh nhân COVID-19 tai thành phố Hồ Chí Minh nẳm 2021. Phương pháp: Thiết kế nghiên cứu mô tả cắt ngang được thực hiện trên 244 nhân viên y tế tại 12 bệnh viện, cơ sở y tế tuyến đầu điều trị COVID-19 tại thành phố Hồ Chí Mình. Sử dụng cấu phần căng thẳng từ thang đo Trầm cảm - Lo âu - căng thẳng (DASS-21) để đánh giá mức độ căng thẳng của nhân viên y tế. Kết quả: Trong 244 nhân viên y tế tham gia nghiên cứu, tỷ lệ có tình trạng căng thẳng là $80,3 \%$, trong đó tỷ lệ có căng thẳng ở mức độ rất nặng, nặng, vửa và nhe lần lướt là: $12,3 \%, 27,9 \%, 22,5 \%$ và $17,6 \%$. Phẩn tích hồi quy logistic cho thây có 2 yếu tố liên quan đến tình trạng căng thẳng ở nhân viên y tế bao gồm: trực tiếp tham gia điều trị bệnh nhân COVID-19 $(\mathrm{OR}=2,14,95 \% \mathrm{CI}: 1,01-4,53 ; \mathrm{p}<0,05)$ và thường xuyên chiu áp lực từ cấp trên trong công việc ( $O R=$ 7,05; 95\%CI: 1,55 - 31,9; $p<0,05)$. Kết luận: Tỷ lệ nhân viên y tế có tình trạng căng thẳng rất cao. Cần

${ }^{1}$ Viện Nghiên cứu Sức khỏe Cộng đồng, Trường Đại hoc Y Dược, Dại họ Huê

̇ệnh viện thành phố Thủ Đức, Hồ Chí Minh

${ }^{3}$ Trường Đại học Y Dược, Đại học Huế

Chiu trách nhiệm chính: Nguyễn Minh Quân

Email: tsminhquanbvtd@gmail.com

Ngày nhận bài: 16.8.2021

Ngày phản biên khoa họ: 12.10.2021

Ngày duyệt bài: 19.10.2021 giảm thời gian làm viêc và tăng cường chính sách đảm bảo an toàn môi trường bệnh viện, đặc biệt quan tâm nhiều hơn cho nhân viên y tế tiếp xúc trực tiếp với bệnh nhân COVID-19 tron quá trình điều trị

Từ khóa: Căng thẳng, nhân viên y tế, COVID-19, thành phố Hồ Chí Minh

\section{SUMMARY \\ STRESS AMONG MEDICAL WORKERS IN SOME HOSPITALS TREATING COVID-19 PATIENTS IN HO CHI MINH CITY}

Background: Medical workers are directly exposed to high levels of negative emotions that appear to increase the risk of long-term consequences such as secondary stress, depressive symptoms or burnout occupation with adverse outcomes for health care quality. Objectives: To assess the stress level of medical workers and its related factors at some hospitals treating COVID-19 patients in Ho Chi Minh City in 2021. Methods: A cross sectional study was conducted on 244 medical workers in 12 hospitals and frontline medical units treating COVID-19 patients in Ho Chi Minh City from September 13 to 20, 2021. Using the stress component of the 21-item Depression, Anxiety and Stress Scale (DASS-21) to assess the level of stress among healthcare workers. Results: A total of 244 medical workers, $80.3 \%$ experienced stress. The prevalence of stress was found to be in the range of mild $(17.6 \%)$, moderate $(22.5 \%)$, severe $(29.7 \%)$, of extremely severe $(12.3 \%)$. Multivariable logistic regression model showed that directly treating COVID-19 patients $(\mathrm{OR}=2.14$, 95\%CI: 1.01 - 4.53; $\mathrm{p}<0.05)$ and often under pressure from superiors at work $(\mathrm{OR}=7.05$; 95\%CI: 1.55 - 31.9; $p<0.05)$ were associated with stress. Conclusion: The prevalence of stress among medical workers was very high. It is necessary to reduce working time and strengthen special policies to ensure the highest level of safety in hospital 